\title{
Acute intensity and motivation to play: comparison of structured and unstructured active video games - a pilot study
}

\begin{abstract}
Objective: To compare intensity (heart rate, oxygen consumption, and perceived exertion) and motivation to play between AVG types (unstructured, UNS-AVG and structured, S-AVG).

Methods: A Pre-test-Post-test experimental study with randomized counterbalanced groups (UNS- and S-AVG type) was performed at the laboratory. Eight male young adults [Mean (SD), age: 19(1) years, body mass index: $23.1(2.4) \mathrm{kg} / \mathrm{m}^{2}$ ] volunteered to participate in this study. Participants underwent a diagnostic evaluation for health status, anthropometric, cardiovascular and metabolic measures. After this, they were paired according to oxygen consumption levels and randomly assigned to each group and performed a 30-min AVG session (UNS-AVG: Kinect Sports Boxing game or S-AVG: Nike Kinect Training game). Heart rate (HR) was recorded during all AVG session. At the end of the session, motivation to play and rating of perceived exertion (RPE) were self-reported. Oxygen consumption estimated for the AVG session was obtained by linear regression line from HR reached during the game and maximal HR during the test session. Unpaired t-test was used to compare game type groups $(\mathrm{P}<0.05)$. Moreover, effect size (ES) was calculated using Cohen's d statistic.
\end{abstract}

Results: Average $\mathrm{HR}(\% \Delta=7.1, \mathrm{P}=0.025, \mathrm{ES}=0.76)$ and oxygen consumption estimated $(\% \Delta=69.5, \mathrm{P}=0.002, \mathrm{ES}=3.63)$ during the sessions were greater for $\mathrm{S}-\mathrm{AVG}$ compared to UNS-AVG. Motivation to play was similar between groups $(\% \Delta=18.2, \mathrm{P}=0.685$, $\mathrm{ES}=0.72)$. RPE was greater for $\mathrm{S}-\mathrm{AVG}$ compared to UNS-AVG group $(\% \Delta=20.6$, $\mathrm{P}=0.045, \mathrm{ES}=1.85$ ).

Conclusion: S-AVG type requires more physical exertion than UNS-AVG; however, these AVG types can be used interchangeably if the goal is motivation. Due to the strong correlation between the HR and oxygen consumption for both AVG types, this data suggests that S-AVG may be a better tool to exercise and probably contribute to reducing sedentary lifestyle more than UNS-AVG in young adults.

Keywords: physical exertion, video games, heart rate, motivation, sedentary lifestyle, oxygen consumption, exercise
Volume 3 Issue I - 2018

\author{
Jorge Luiz Brito-Gomes, ', ', Leonardo dos \\ Santos Oliveira, ${ }^{2}$ Raphael José Perrier- \\ Melo, , ', Juliette, Noadya Costa Santos, ', ${ }^{2}$ \\ Fernando José de Sá Pereira Guimarães, ${ }^{2}$ \\ Manoel da Cunha Costa ${ }^{2}, 3$ \\ 'Student of the Post Graduate Program in Physical Education, \\ Pernambuco State University (UPE), Brazil \\ ${ }^{2}$ Human Performance Laboratory, Pernambuco State University \\ (UPE), Brazil \\ ${ }^{3}$ Professor Phd of the Post Graduate Program in Physical \\ Education, Pernambuco State University (UPE), Brazil
}

Correspondence: Jorge Luiz de Brito Gomes, Student of the Post Graduate Program in Physical Education, Pernambuco State University (UPE), Brazil, Zip Code 50I00-130, Tel 3183-3378, Email jorgelbritog@hotmail.com

Received: November 29, 2017 | Published: February 08, 2018

\section{Introduction}

Sedentary lifestyle is a serious health problem in the world and, in the Brazil, $80 \%$ of the population presents this behavior with a lower level of physical activity ${ }^{1}$ This behavior is associated with serious health risks and inversely related to physical activity (PA). Low levels of physical activity may develop or aggravate chronic degenerative diseases; however, this PA promotion prevents and treats diseases such as hypertension, obesity, and diabetes. Therefore, PA is important and is conceptualized as any bodily movement with sufficient intensity to elevate the energy expenditure above resting levels. ${ }^{2}$

Due to the globalization and technological advancement part of the population spent more hours on "screen time" (triad of watching $\mathrm{TV}$, using computer and playing inactive video games). ${ }^{3}$ In general, video games (traditional ones - with joysticks) have been widely used by children and young adults. However, they provide a low increase in body movement and demand less oxygen consumption compared to stand watching TV, for example. ${ }^{4}$ These may discourage a regular practice of PA and favor the sedentary lifestyle. ${ }^{5}$
According to the official guidelines of exercise and PA, young adults should perform 30 to 60 minutes of moderate intensity (50-69\% of maximum heart rate) in at least 5 days a week. ${ }^{6}$ To change habits of "screen time", a new form of video games, named active video games (AVG) has been used to increase levels of daily PA. Previous studies demonstrated that AVG reduce the hypokinesia caused by the sedentary lifestyle and may promote health, raising the heart rate (HR) and energy expenditure in acute analyses ${ }^{7-10}$

Commercially available AVG systems present several kinds of consoles such as Xavix, PlayStation Eye Toy, Nintendo Wii and Xbox $360^{\circ}$ with Kinect are found. Nintendo Wii may request the same metabolic equivalent compared to Xavix and other consoles ${ }^{7,11}$ and is used to analyze the body balance. ${ }^{12}$ In another hand, AVGs from Xbox $360^{\circ}$ with Kinect that are used standing with no joystick, it requires greater metabolic equivalent and oxygen consumption compared to Nintendo $\mathrm{Wii}^{10}$ also greater energy expenditure, oxygen consumption and heart rate. ${ }^{13}$

In addition, scientific research with AVG has used, especially, unstructured or structured games. Unstructured AVG has been applied 
to recreation, motivation or rehabilitation ${ }^{14-17}$ Structured AVG has been used to improve levels of physical fitness in virtual reality because they follow the principles of sports training ${ }^{14,18,19}$ However, few studies have compared these types of AVG, showing long-term effects (pre-post analysis) on aerobic capacity ${ }^{20}$ physical effort and motivation $^{21}$ after 6 -week training. Consequently, a few scientific data about these variables on these types of AVG in a single session.

Due to the widespread use of AVG, health professionals should develop a practical knowledge, especially about their benefits and ways of using in various clinical contexts. Thus, the aim of this study was to compare physical effort (heart rate, oxygen consumption, and perceived exertion) and motivation to play between AVG types (unstructured, UNS-AVG and structured, S-AVG). The hypothesis is the S-AVG elicits greater physical effort and motivation to play than unstructured counterparts.

\section{Methods}

\section{Participants and ethical issues}

Participants were recruited from the Universidade de Pernambuco (UPE), Recife in the Brazil, via word of mouth advertising and social media websites. Eight male young adults [Mean (SD), age: 19(1) years, body mass index: $\left.23.1(2.4) \mathrm{kg} / \mathrm{m}^{2}\right]$ volunteered to participate in this study. Inclusion criteria were: university students, $19 \leq$ aged $\leq 24$ years, being apparently healthy (PAR-Q) and physically inactive (three months with no practice of structured physical activities) and no experience with AVG. Participants was excluded for missing the sessions or failing to perform the complete AVG session. Ethical approval for this study was gained from the Research Ethics Committee at the UPE (number: 577.277). Participants were informed about the objective, procedures and potential risks of this study and provided a written informed consent. ${ }^{22}$

\section{Study design}

A Pre-test-Post-test experimental study with randomized counterbalanced groups (unstructured- and structured-AVG type) was performed at the laboratory with similar conditions among measurements days (temperature: $22-24^{\circ} \mathrm{C}$, relative humidity: $40-60 \%$, atmospheric pressure: $\approx 760 \mathrm{mmHg}$ ). Participants completed three visits. At the first, participants underwent a diagnostic evaluation for health status, anthropometric, cardiovascular and metabolic measures. After $48 \mathrm{~h}$, at the second, participants were paired according to oxygen consumption levels and randomly assigned to an unstructured- (UNSAVG) or structured-AVG (S-AVG) group, and performed an AVG familiarization. After $48 \mathrm{~h}$, at the third visit, each group performed their AVG session.

For all visits, participants were instructed to wear minimal clothing and appropriate footwear for physical exercise, to avoid moderate or vigorous exercise for 24 hours prior to visits, to feed 1-2 hours before the assessment and to refrain from ingesting beverages containing caffeine, others substance stimulants or alcohol during the 24 hours preceding the visits.

Table I Differences between unstructured (UNS-AVG) and structured (S-AVG) Brito-Gomes et al. ${ }^{20}$

\section{Procedures}

\section{Anthropometry}

Body weight (in kilograms) was measured by a mechanical scale (Filizola, Brazil), nearest to $0.1 \mathrm{~kg}$. Height (in centimeters) was measured by a wooden stadiometer; nearest to $0.01 \mathrm{~m}$. Anthropometric measurements were performed by a single trained professional with standardized international techniques. ${ }^{23}$ Height and body mass were used to calculate the body mass index, reported as kilograms per square meter.

\section{Cardiovascular measures}

All cardiovascular measurements were performed after rest of five minutes in a seated position. Heart rate (HR) was measured by a heart rate monitor (FT1, Polar, Finland) (and was used to calculate the \%HR using: $\% \mathrm{HR}=$ (residual $\mathrm{HR} \times$ intensity)-rest $\mathrm{HR}$ ) and systolic (SBP) and diastolic (DBP) blood pressure were measured by an automatic blood pressure monitor (Omron HEM 7113; Omron Healthcare Co. Ltd., Japan).

\section{Test session}

Oxygen consumption $(\mathrm{mL} / \mathrm{kg} / \mathrm{min})$ was analyzed by a submaximal test on a cycle ergometer (EC-1600, Cateye Ergociser, Japan), following the Astrand-Ryhming protocol. ${ }^{24}$ A metabolic gas analyzer (Metalyzer ${ }^{\circledR}$, Cortex, Germany) with a face mask with adult head cap (Metalyzer, Germany) was used. HR was continuously registered by an electrocardiograph with three derivations (Micromed, Brazil) using the PC Elite Software 3.0 (Micromed, Brazil).

\section{Familiarization}

UNS-AVG group (Kinect Sports Boxing game) performed 20 min of gaming and watched tutorial videos of the game in order to use it in a better form. S-AVG group (Nike Kinect Training game) performed a brief evaluation $(20 \mathrm{~min}$ ), which this AVG provides to prescribe the exercises on the virtual reality. Also, this group watched tutorial videos with the same objective proposed for UNS-AVG group.

\section{AVG session}

All AVG sessions were completed with an Xbox 360 Kinect game console (Microsoft, USA). A multimedia projector (Power lite S10+, Epson, Japan) with a sound amplifier (OCM 126 professional, Oneal, Brazil) were used as AVG device. The setup lab measurement was described previously. ${ }^{14,20}$ Each group performed their session (UNSAVG or S-AVG) for 30 minutes. HR was recorded by a heart monitor (FT1, Polar, Finland) during all AVG session. At the end of the session, motivation to play by Visual Analog Scale (VAS) ${ }^{25}$ adapted for $\mathrm{AVG}^{26}$ and rating of perceived exertion (RPE) on a scale of 6-20 (Borg Scale $)^{27}$ were self-reported. Oxygen consumption for the AVG session was obtained by linear regression line from HR reached during the game and maximal HR during the test session. Table 1 illustrates some differences between UNS-AVG and S-AVG.

\begin{tabular}{|c|c|c|}
\hline $\begin{array}{l}\text { UNS- } \\
\text { AVG }\end{array}$ & $\begin{array}{l}\text {-Activities that do not mimic formal exercises but rather sporting movements and general body movements. } \\
\text {-Players are free to move as they wish during game play and there is no formal progression to higher levels of } \\
\text { physical activity difficulty as game play progresses }\end{array}$ & $\begin{array}{l}\text { Boxing, Volleybal, Table } \\
\text { tennis, Dance Dance } \\
\text { Revolution }\end{array}$ \\
\hline
\end{tabular}




\section{Statistical analyses}

Gauss distribution was confirmed by a Shapiro-Wilk test for all data. Data were reported by mean (SD or $95 \%$ interval confidence). Unpaired t-test was used to compare game type groups (UNS-AVG vs. S-AVG). Multiple linear regressions was applied to estimate oxygen consumption of AVG session from HR reached during the game and maximal HR and oxygen consumption during the test session. Effect size (ES) was calculated using Cohen's d statistic by Psychometrica calculator, which a $\mathrm{d}=0.01-0.20$ was considered small, $\mathrm{d}=0.21-0.50$ moderate, $\mathrm{d}=0.51-0.80$ large, and $\mathrm{d} \geq 0.80$ very large effect. The level of significance was set at $\mathrm{P}<0.05(\alpha=0.05)$.

\section{Results}

Table 2 shows baseline data of participants. The oxygen consumption of participants was classified as regular from the American College of Sports Medicine and the American Heart Association. $^{28}$

Table 2 Baseline data (mean \pm SD) of male young adults by AVG type $(n=8)$

\begin{tabular}{lll}
\hline Variable & UNS-AVG $(\mathrm{n}=4)$ & S-AVG $(\mathrm{n}=4)$ \\
\hline Age (years) & $19.0 \pm 1.0$ & $19.0 \pm 1.0$ \\
Weight $(\mathrm{kg})$ & $72.3 \pm 10.2$ & $71.7 \pm 13.7$ \\
Heigth $(\mathrm{m})$ & $1.70 \pm 0.05$ & $1.70 \pm 0.06$ \\
BMI $\left(\mathrm{kg} / \mathrm{m}^{2}\right)$ & $22.6 \pm 2.0$ & $23.6 \pm 3.3$ \\
$\begin{array}{l}\text { Resting systolic blood pressure } \\
\text { (mmHg) }\end{array}$ & $131.0 \pm 8.8$ & $124.7 \pm 10.8$ \\
$\begin{array}{l}\text { Resting diastolic blood pressure } \\
\text { (mmHg) }\end{array}$ & $69.8 \pm 4.5$ & $68.3 \pm 10.0$ \\
$\begin{array}{l}\text { Resting heart rate }(\mathrm{bpm}) \\
\text { Oxygen consumption }(\mathrm{mL} / \mathrm{kg} / \mathrm{min})\end{array}$ & $37.7 \pm 4.5$ & $71.0 \pm 9.0$ \\
\hline
\end{tabular}

BMI, Body mass index

HR and oxygen consumption during the test session showed a strong correlation for UNS-AVG $\left(\mathrm{R}^{2}=0.968, \mathrm{P}=0.008\right)$ and $\mathrm{S}-\mathrm{AVG}$ $\left(\mathrm{R}^{2}=0.992, \mathrm{P}=0.002\right)$ groups. Figure 1 shows $\mathrm{HR}$ and oxygen consumption comparisons between UNS- and S-AVG groups. Average HR ( $\mathrm{t}=-4.15, \mathrm{P}=0,025, \% \Delta=7.1)$ and oxygen consumption $(\mathrm{t}=-5.12, \mathrm{P}=0.002, \% \Delta=69.5)$ were greater for $\mathrm{S}-\mathrm{AVG}$ compared to UNS-AVG. Very large effects were found for maximal HR and oxygen consumption in relation to the AVG type (Figure 1).

From the mean of the percentage of HR reserve, the UNS-AVG session was considered as a physical activity of moderate intensity while the S-AVG session as vigorous intensity, according to American College of Sports Medicine. ${ }^{28}$

The RPE and motivation to play for UNS-AVG and S-AVG groups are presented in Figure 2. Motivation to play was similar between groups $(\mathrm{t}=-2.48, \mathrm{P}=0.685, \% \Delta=-16.4, \mathrm{ES}=0.72)$. A large effect was found for RPE, which S-AVG was greater than UNS-AVG group $(\mathrm{t}=0.71, \mathrm{P}=0.045, \% \Delta=22.4, \mathrm{ES}=1.85)$. According to American College of Sports Medicine, UNS-AVG was deemed as moderate (RPE: 12 to 13 points) and S-AVG as vigorous intensity (RPE: 14 to 17 points). ${ }^{28}$

\section{Discussion}

In the present Pre-test-Post-test experimental study, we compared physical exertion (HR, oxygen consumption, and perceived exertion) and motivation to play between the UNS-AVG and S-AVG type. Our data confirmed the hypothesis that S-AVG elicits greater physical exertion compared to the UNS-AVG. However, the motivation to play was similar between the AVG types. Therefore, S-AVG type requires more physical exertion than UNS-AVG; however, they can be used interchangeably if the goal is motivation.

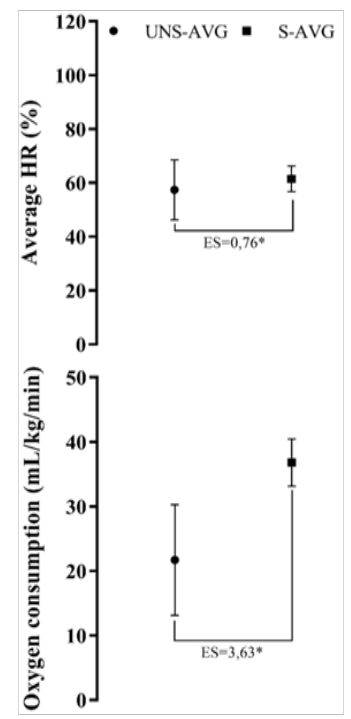

Figure I Average and maximal heart rate (HR) and oxygen consumption of male young adults between unstructured (UNS-AVG) and structured (S-AVG) active video games. Data reported as mean and $95 \%$ interval confidence. ES, Effect size (Cohen's $d)$. *Significant difference $(P<0.05)$.

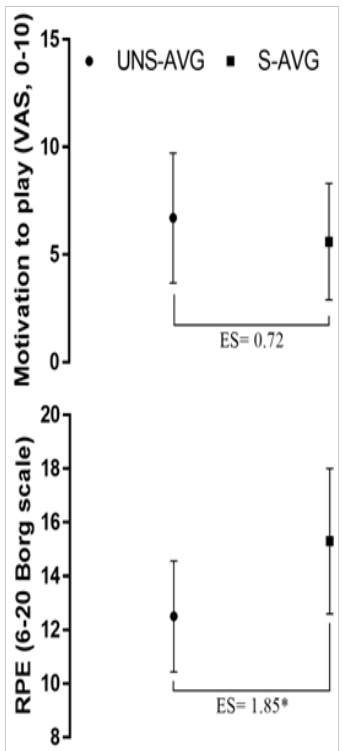

Figure 2 Motivation to play (Visual Analog Scale, VAS: $0=$ low, 10=high) and rating of perceived exertion (RPE, Borg scale: $6=$ no exertion at all, $20=$ maximal exertion) of male young adults between unstructured (UNS-AVG) and structured (S-AVG) active video games. Data reported as mean and $95 \%$ interval confidence. ES, Effect size (Cohen's $d)$. * Significant difference $(P<0.05)$. 
According to American College of Sports Medicine ${ }^{28}$ both AVG type met the recommendations for physical activity as moderate-tovigorous intensity exercise. However, S-AVG elicited an effect almost $70 \%$ greater than the UNS-AVG for oxygen consumption and almost $36 \%$ greater for maximal HR. In addition, UNS-AVG was considered moderate (RPE: 12 to 13 points) and S-AVG as vigorous intensity (RPE: 14 to 17 points). Then, health professionals should understand the best way to use the AVG types, according to the need of the individual person. Moreover, AVG (as aerobic exercise) combined with resistance training may confer additional health benefits. ${ }^{28}$

For UNS-AVG, similar results have been presented for HR..$^{29,30,31}$ Young adults have shown an average of $58 \%$ reserve HR during a 15 -min Wii Sports Boxing trial ${ }^{30}$ an average of 50 to $69 \%$ of maximal HR during a 10-min Kinect Sports Boxing trial ${ }^{29}$ and Kinect Sports Boxing $>160 \mathrm{bpm}$ (moderate intensity). Even with differences between console types and duration of activity, there seems to be clear scientific information about the moderate intensity of boxing in a virtual environment.

To our knowledge, to this present data, there are no acute investigations analyzing the Nike Kinect Training game. Nevertheless, other studies were performed with different S-AVG, such as the Your Shape Fitness Evolved game (Xbox 360 Kinect) and Wii Fitness game (Nintendo Wii). Falcade et al. ${ }^{32}$ investigated young adults in a 3-minute Your Shape Fitness Evolved session and they verified a significant increase of the HR near to $181 \mathrm{bpm}$, considered a vigorous intensity according to American College of Sports Medicine ${ }^{28}$ In another study, adults performed a Wii Fitness session and the HR has increased to about $180 \mathrm{bpm}^{33}$ even though being a console that presents AVG with lower physiological costs in comparison to Xbox 360 Kinect.

Oxygen consumption in our UNS-AVG session was similar to study by Perusek et al. ${ }^{34}$ with direct metabolic analysis in 30 young adults in a virtual boxing session $(19.6 \mathrm{~mL} / \mathrm{kg} / \mathrm{min})$. Thus, knowing that a direct analyze is the gold standard but expensive, this present analysis shows similar values that may be trustful to estimate the oxygen consumption during the AVG. The present work provides the first reference for oxygen consumption in response a 30-min Nike Kinect Training session. A study with similar S-AVG (Your Shape Fitness Evolved game) showed an oxygen consumption near to 38.2 $\mathrm{mL} / \mathrm{kg} / \mathrm{min}$, presenting a significant difference from the rest. ${ }^{32}$

In addition, analyzing the metabolic elicit and turned on the intensity of physical activities, by the literature is possible to divide the oxygen consumption by 3.5 and estimate the metabolic equivalents (METs). ${ }^{35}$ Thus, 6.2 METs and 10.5 METs were verified for UNS-AVG and S-AVG in our study, respectively, confirming the moderate (3-6 METs) and vigorous intensity ( $>7$ METs) discussed above. ${ }^{28}$ Different results were showed by Taylor et al. ${ }^{36}$ with lower MET values (2.97 \pm 1.16 ; light-moderate activity) for UNS-AVG. For S-AVG, young adults performed a 3-min Your Shape Fitness Evolved trial at 7.3 METs. ${ }^{28}$ Therefore, this virtual type of structured physical activity may be most efficient than UNS-AVG as a form to reduce the sedentary style because of the greater elicitation of intensity.

In general, UNS-AVG is used as a form to motivate people to move their body and is considered more motivating than structured physical education activities. ${ }^{26,37}$ However, in this study, AVG type presented the same motivation to play levels. Although the S-AVG showed the highest metabolic elicitation, it should be possible the fact of the participants can do the activities correctly motivating themselves to continue with a good enjoyment as have been seen in others UNS-AVG, which were made to keep a high enjoyment during the session. ${ }^{21}$ Also, the novelty of using new forms of virtual reality to exercise may motivate them to play, even though a structured form of exercising that sometimes may be no motivating. ${ }^{13,38}$ In this case, the S-AVG can be a good tool too to initiate physical activities, because, the participants may be as motivated as gaming a UNS-AVG.

A limitation of this study was to examine only young men. Since men and women have unique characteristics, motivation to play promote exercise economy and over this point, may change the HR, oxygen consumption and perceived exertion in dependency to different AVG used to each population ${ }^{39}$ Others sex and special population (as hypertensive, obese and diabetics) must be tested to analyze the cardiovascular changes (blood pressure, double product, and HR variability) related to oxygen consumption and motivation to play these two types of AVG, especially the structured ones. In practical terms, this study advances the knowledge of the "screen time" using in an active form. It must be possible to reduce the negative effects of sedentary lifestyle found in the population, promoting physical fitness with motivation to play in a virtual reality.

\section{Conclusion}

S-AVG can be a vigorous exercise according to the international guidelines, showing greater values of average and maximal HR and oxygen consumption compared to UNS-AVG for young adults. Moreover, both AVG types can be used to motivate to exercise. Due to the strong correlation between the HR and oxygen consumption for both AVG types, this data suggests that S-AVG may be a better tool to exercise and probably contribute to reducing sedentary lifestyle more than UNS-AVG in young adults.

\section{Acknowledgements}

None

\section{Conflict of interest}

The author declares no conflict of interest.

\section{References}

1. Malta DC, Silva JBD. Plano de ações estratégicas para o enfrentamento das doenças crônicas não transmissíveis no brasil após três anos de implantação, 2011-2013. Epidemiologia e Serviços de Saúde. 2014;23(3):389-395.

2. Caspersen C, Powell K, Cristensen G. Physical activity, exercise and physical fitness: definitions and distinctions for health-related research. Public Health Reports. 1985;100(2):126-131.

3. Christie B, Trout J. Rather than contribute to a sedentary lifestyle, these games demand activity from the players. Interactive Video Games in Physical Education. 2007;78:29-45.

4. Lanningham FL, Foster RC, Mccrady SK, et al. Activity promoting games and increased energy expenditure. J Pediatr. 2010;154(6):819823.

5. Graves LEF, Ridgers ND, Williams K, et al. The physiological cost and enjoyment of Wii Fit in adolescents, young adults, and older adults. Journal of Physical Activity \& Health. 2010;7(3):393-401.

6. Haskell WL, Lee IM, Pate RR, et al. Physical activity and public health: updated recommendation for adults from the american college of sports medicine and the american heart association. Med Sci Sports Exerc. 2007;39(8):1423-1434 
7. Bailey BW, Mcinnis K. Energy cost of exergaming: a comparison of the energy cost of 6 forms of exergaming. Arch Pediatr Adolesc Med. 2011;165(7):597-602.

8. Graves LEF, Ridgers ND, Stratton G. The contribution of upper limb and total body movement to adolescents' energy expenditure whilst playing Nintendo Wii. European Journal of Applied Physiology. 2008;104(4):617-623.

9. Roemmich JN, Lambiase MJ, McCarthy TF, et al. Autonomy supportive environments and mastery as basic factors to motivate physical activity in children: a controlled laboratory study. International Journal of Behavioral Nutrition and Physical Activity. 2012;13:1-8.

10. Smallwood SR, Morris MM, Fallows SJ, et al. Physiologic responses and energy expenditure of kinect active video game play in schoolchildren. Archives of Pediatrics \& Adolescent Medicine. 2012;166(11):1005-1009.

11. Mellecker RR, Lanningham-Foster L, Levine J, et al. Energy intake during activity enhanced video game play. Appetite. 2010;55(2):343-347.

12. Wikstrom EA. Validity and reliability of nintendo wii fit balance scores Journal of Athletic Training. 2012;47(3):306-313

13. O'Donovan C, Hirsch E, Holohan E, et al. Energy expended playing xbox kinecttm and wiitm games: a preliminary study comparing single and multiplayer modes. Physiotherapy. 2012;98(3):224-229.

14. Perrier MRJ, Brito GJL, Melo OSF, et al. Acute responses of heart rate and blood pressure in a session of active video games in young healthy males: a pilot study. Rev Ter Ocup Univ São Paulo. 2014;24:259-266.

15. Hart GM, Johnson B, Stamm B, et al. Effects of video games on adolescents and adults. Cyberpsychology \& Behavior. the impact of the internet. Multimedia and virtual reality on behavior and society. 2009;12(1):6365.

16. Pompeu JE, Alonso TH, Masson IB, et al. Os efeitos da realidade virtua na reabilitação do acidente vascular encefálico: Uma revisão sistemática. Revista Motricidade. 2014;10(4):111-122.

17. Rendon AA, Lohman EB, Thorpe D, et al. The effect of virtual reality gaming on dynamic balance in older adults. Age and Ageing. 2012;41(4):549-552.

18. Adamo KB, Rutherford JA, Goldfield GS. Effects of interactive video game cycling on overweight and obese adolescent health. Applied Physiology, Nutrition, and Metabolism. 2010;35(6):805-815.

19. Warburton DER, Bredin SSD, Horita LTL, et al. The health benefits of interactive video game exercise. Appl Physiol Nutr Metab. 2007;32(4):655663.

20. Brito GJL, Perrier MRJ, Wikstrom EA, et al. Improving aerobic capacity through active videogames: A randomized controlled trial. Revista Motriz. 2015;21(3):305-311.

21. Brito GJL, Perrier MRJ, Oliveira SFM, et al. Physical effort, Energy expenditure, and motivation in structured and unstructured active video games: A randomized controlled trial. Human Movement. 2016;17:190 198.

22. Harriss DJ, Atkinson G. Ethical standards in sports and exercise science research: 2016 update. Int J Sports Med. 2015;36(14):1121-1124.
23. Stewart A, Marfell JM, Olds T, et al. International society for the advancement of kinantropometry. International Standards for Anthropometric Assessment. Australia; 2012.

24. Astrand PO, Ryhming I. A nomogram for calculation of aerobic capacity (physical fitness) from pulse rate during submaximal work. $J$ Appl Physiol. 1954;7(2):218-221

25. Ahearn P. The use of visual analog scale in mood disorders: A critical review. J Psychiatr Res. 1997;31(5):569-579.

26. Thin AG, Brown C, Meenan P. User experiences while playing dancebased exergames and the influence of different body motion sensing technologies. International Journal of Computer Games Technology. 2013;1:1-7.

27. Borg G. Escala de Borg para a Dor e o Esforço Percebido. Manole, São Paulo: Brazil; 2000.

28. Garber CE, Blissmer B, Deschenes MR, et al. American college of sports medicine position stand. Quantity and quality of exercise for developing and maintaining cardiorespiratory, musculoskeletal, and neuromotor fitness in apparently healthy adults: guidance for prescribing exercise. Medicine and Science in Sports and Exercise. 2011;43(7):1334-1359.

29. Brito GJL, Perrier MRJ, Albuquerque FL, et al. Comportamento da frequência cardíaca durante uma sessão com diferentes vídeo games ativos Manual Therapy, Posturology and Reabilitation Journal. 2014;12:81-95.

30. Donovan OC, Hussey J. Active video games as a form of exercise and the effect of gaming experience: a preliminary study in healthy young adults. Physiotherapy. 2012;98(3):205-210.

31. Pereira SVVN, Brito GJL, Perrier MRJ, et al. Revista Ciência e Movimento. Accepted ahead of print: Brazil; 2018.

32. Falcade A, Baroncini L, Hanna E, et al. Análise do consumo de oxigênio, da frequência cardíaca e equivalentes metabólicos através de um videogame ativo. Inspirar. 2013;5:20-24.

33. Douris PECD, Onald BRMCD, Espi FRV, et al. Comparison between nintendo wii fit aerobics and tradicional aerobic exercise in sedentary young adults. J Strength Cond Res. 2012;26(4):1052-1057.

34. Perusek K, Sparks K, Little K, et al. A comparison of energy expenditure during "wii boxing" versus heavy bag boxing in young adults. Games for Health Journal. 2014;3:21-24.

35. Jetté M, Sidney K, Blümchen G. Metabolic equivalents (METS) in exercise testing, exercise prescription, and evaluation of functional capacity. Clinical Cardiology. 1990;13(8):555-565.

36. Taylor LM, Maddison R, Pfaeffli LA, et al. Activity and energy expenditure in older people playing active video games. Arch Phys Med Rehabil. 2012;93(12):2281-2286.

37. Lwin MO, Malik S. The efficacy of exergames-incorporated physical education lessons in influencing drivers of physical activity: A comparison of children and pre-adolescents. Psychology of Sport and Exercise. 2012;13:756-760.

38. Thin AG, Hansen L, Mceachen D. Flow experience and mood states while playing body movement-controlled video games. Games and Culture. 2011;6(5):414-428. 